\title{
Romania: \\ Traditional Conflict Resolution Mechanisms Used by the Roma Communities
}

\author{
Ciprian SANDU
}

\begin{abstract}
Even though there have been numerous studies on the quality of life of the Romani (Roma) communities, their role in society, marginalization or poverty, at this time, there are few studies that show how these communities understand and regard conflict and the methods (especially the traditional ones) that they use to solve these problems. Previous research has provided evidence to show that Romani people have developed their own indigenous system of justice, rather than relying on official agents of social control to deal with disputes in their communities. Through the use of the ethnographic approach, using participatory observation and the interview as methods of data collection, the present study aims to present how Roma people use and impose justice in their communities through a better understanding of their moral codes.
\end{abstract}

Keywords: Romani, Roma people, traditional conflict resolution, Stabor, Divan, shame, Gorger, Romanipen.

\author{
Ciprian SANDU \\ Mediator, Transylvanian Institute \\ of Mediation \\ E-mail: ciprian.sandu@fspac.ro
}

Conflict Studies Quarterly

Issue 22, January 2018, pp. 95-108

DOI:10.24193/csq.22.6

Published First Online: 01/10/2018

\section{Introduction}

Indigenous community justice and the traditional ways of conflict resolution saw a resurgence in interest over the recent years. Even so, very little is known of the role of justice among the Roma people and their traditional ways of conflict resolution (at least this is the case in Romania) which this research will aim to redress. In our opinion, the most important reason for this lack of knowledge in our country is the fact that, due to their way of living, the Roma people (especially the ones who preserved their nomadic lifestyle) have been regarded with both curiosity and suspicion. Curiosity be- 
cause they are a closed community with reluctance towards the wider society (Gadjo in Romani language - term used by the Roma people to name the non-Gypsies) and suspicion because they are often labeled as deviant and "outlaws" (somehow the meaning of the word Gypsy comes from its connotations of illegality and irregularity) through discourse in the media, by the police and by politicians (Richardson, 2006).

Despite the number of negative headlines and perception of the majority of society, evidence suggests that Roma communities are far from lawless and abide by a strict moral code, one that ironically, may at times lead them into conflict with the majority community (Morris, 2001). Such evidence has emerged from a number of in-depth studies aimed at understanding the lifestyle and culture of this group and how this may impact their attitudes towards crime and deviance (James, 2005, 2006, 2007; Bancroft, 2005; Vanderbeck, 2005; Dawson, 2000; Gmelch, 1986; Okely, 1983).

Alongside this, and most important for the aim of this article, previous research has provided evidence that Romani have developed their own system of justice, instead of relying on official agents of social control to deal with disputes in their communities. There is some evidence to suggest that they adopt similar strategies to small-scale tribal communities (Okely, 2005; Weyrauch, 2001).

The purpose of this article will be to explore the varying methods used by Roma communities when managing transgressions from the moral codes established among them. This will be undertaken within the context of a review of literature on how various communities have dealt with transgressions among their members.

\section{Literature review}

The methods used by small-scale tribal communities can vary from informal resolutions to formal community justice (Bohannan, 1957; Leach, 1954). These methods can range from the informal strategy of avoidance in dealing with deviants, whereby deviants are ignored for a specific period of time (Leach, 1954), to ostracism and exile for deviant transgressions (Colson, 1974), to blood feuds used as a means to seek reparation for a deviant act (Lee, 1979). At the more formal end of informal community justice, evidence has shown how tribal communities operate a court system which takes precedence over state sanctions (Gibbs, 1963; Bohannan, 1957; Coser, 1956; Leach, 1954). Evidence suggests that Roma operate similar systems to those mentioned above, using both indigenous practices (shaming, avoidance, ostracization or blood-feuds) and the more "formal" court known as Stabor (the gypsy court or gypsy judgement).

In recent years, we can observe an increased debate around the obligations of the state and a recognition that governance is no longer the exclusive responsibility of the state. Governance is conducted from varying sites and at differing levels within and between nation states (Edwards \& Hughes, 2005). Alongside this, many groups within a nation 
state actively resist state governance in favor of less formal locally administered justice, and, as such, communities have developed their own agendas in the delivery of justice. Stenson (2005) argues that this form of justice can be understood through the notion of "governance from below" which he refers to as "folk bio-politics" (Stenson, 2005). Many communities are thus able to develop informal systems of community justice based upon folk modes of expertise that are more able to understand the needs of their community and enables them to provide justice with little recourse to official agents of social control. "Governance from below" enables marginalized groups to reclaim power in decision-making processes pertaining to justice. Through the use of this, members are able to understand the specific needs of their community, enabling them to develop appropriate sanctions for wrongdoers. As such, many communities have little recourse to official agents of social control. There are however varying modes of justice delivered among community members. Despite this, the overarching principles of community justice are the "swift" and "visible" delivery of justice, with shame being at the heart of all forms of justice. Through this, communities are able to deliver justice that is underpinned by the ideology of restorative justice.

Evidence would suggest that many communities have adopted alternative means to ensure the delivery of justice replacing the forms of justice offered by the state (Okely, 2005;Weyrauch, 2001, Caffery \& Mundy, 1997; Gibbs, 1963; Bohannan, 1957; Coser, 1956; Leach, 1954; Chereji \& Pop, 2014). If we turn to the work of many early and influential anthropological studies that focus on small-scale tribal communities, the complexity of indigenous community justice becomes more apparent. Pfohl (1981) asserts that in small-scale societies "rituals of primary ordering" have been adopted, enabling such communities to prevent deviation from norms, thus securing a shared sense of belonging and identity (p. 75). This sense of shared belonging suggests that, within these small-scale communities, the focus is on the reconciliation of the offender back into their social group (Raybeck, 1988). There are varying means to deal with transgressions. These differ in terms of formality, including moot courts, fighting and blood feuds, gossip and avoidance (Raybeck 1988; Pfohl, 1981; Gibbs, 1963; Bohannan, 1957; Coser, 1956; Leach, 1954). Evidence would suggest that similar methods have been employed by the Roma communities (Okely, 2005; Weyrauch, 2001; Caffery\& Mundy, 1997; Acton, Caffery, \& Mundy,1997).

According to the early anthropological studies regarding the traditional ways of conflict resolution, their purpose is to seek an amicable resolution to a transgression from the rules and law (Gibbs, 1963; Coser, 1956, Bohannan, 1957; Leach, 1954), an important feature being the restoration of the offender back into the community, with no hard feelings from the rest of the group (Scott, 1976). Another important aspect is the fact that this "folkish" way of dealing conflicts has a much greater influence over community members than the legal system of the state in which the community lives. For 
example, offenders punished by the state legal system would also be punished by their community on their return.

As presented above, all these folk means of conflict resolution can be included in what is now knows as restorative justice. Restorative justice has become a widely used concept, so much that Braithwaite (2002) refers to this system of justice as a global social movement. Marshall (1996) proffers a number of key principles that represent restorative justice. These include (a) the acceptance of and the need for personal involvement, that is, by those harmed and the offender(s), (b) the problem should be seen in a social context, (c) punishment should be forward looking and preventative and, finally, (4) practices should be flexible (p. 28). The development of restorative justice has often been credited to the work of Braithwaite (Blagg, 2008); nonetheless, as Walgrave (2008) concedes, the principles of this form of justice can be traced back to many primitive societies. The use of restorative justice has been well documented among many indigenous populations, such as Navajo peacemaker circles, in which all parties meet with a peacemaker who allows both groups to come to an amicable resolution (Coker, 2006). Similarly, the use of family conferencing in New Zealand has its roots in restorative justice (Van-Ness, Morris, \& Maxwell, 2001). Aboriginal ceremonies based on traditional tribal law focus upon the notion of cosmology, yet within this system there may be fighting, physical payback, cursing, and sorcery. Regardless, offenders are shamed, but are also reunited with their community once the punishment has been dealt (Blagg, 2008). Hawaiian islanders have use their own practice, very resembling with the ones above, named ho'oponopono. Literally, this practice means "setting things right" and involves a family coming together to discuss interpersonal conflicts under the guidance of a leader. Also, the Abkhazian people have long practiced mediation to resolve disputes within their group and among the tribes in the surrounding areas. The mediation process was guided by an elder who used shame as the main approach to resolve the conflict and reintegrate the parties in the community.

\section{Methodology}

Through the ethnographic approach, using participatory observation and the interview as data collection methods, this study aims to outline how the Roma people use and enforce justice in their community through a better understanding of their moral codes.

The research is based primarily on ethnographic methods supported by three research questions:

a. How do the Roma communities in Romania manage their conflicts?

b. What rules and / or customs use the Roma in response to conflict and transgression from the moral codes?

c. When and how are these methods used? 
The methodology chosen for studying these communities leads us towards an ethnomethodological approach, as thought by sociologist Harold Garfinkel. He claims that the social is a process, a result of the permanent activity of the members of society that have a common sense and a practical knowledge deposit that they use in order to communicate, to make decisions, to reason, in a natural and regularly way, in the most ordinary activities of everyday life. Starting from this premise, ethnomethodology applies to everyday acts in order to identify among them the procedures and interactions involved in building social acts. The central idea is that the means by which members produce and steer their daily affairs are the same as those that they use to justify these daily events. Moreover, the term ethnography literally means "writing culture" and is based on the study of a culture (a group) in its natural environment. Deriving from anthropology, ethnography has retained some of its key principles, especially that research should seek to discover the views and experiences of a group sharing the same interests through a longitudinal study of mixed methods (emphasis is placed on complementarity, mutual validation of data tools and sources, effective and comprehensive coverage of the studied topics) involving observation as a determining factor data collection. The design of the research has been done to ensure that the methods used will enable a rich source of qualitative data, in order to take into account the needs and vulnerabilities specific to Roma communities. As mentioned earlier, we have adopted a multimodal strategy, incorporating a number of qualitative methods such as interviews, participatory observation and life stories.

\section{Instruments}

Participatory observation is an essential method for adapting other working methods to the specific conditions encountered in the community. The first information, which is obtained through observation, is essential to the success of the case study. At this stage, the researcher can decide the importance of interviewing some categories of respondents, how to approach them and the subject, what kind of additional information should be obtained, reordering and restructuring the themes in the interview guides. Furthermore, the observation method provides a significant amount of useful information to achieve the purpose of the study. There are many contextual elements that define the studied group which can be captured by the observation method in a short amount of time.

The semi-direct or semi-structured interview is between standardized and non-directive discussions. The interviewer has a series of questions or themes, but he or she only uses them to focus the discussion on the topics studied, so the interviewer is encouraged to express his or herself freely, approaching the themes in the desired order. Through the semi-structured interview, human subjectivity can be investigated in an interactive way, which is not accessible through other methods, except when discussing future 
intentions. In addition to this first advantage, the interview makes it possible to collect otherwise very challenging and expensive data, such as records on human behaviors.

\section{Participants}

For the purposes of this study, I have chosen a small Roma community near Târgu Cărbunești (Gorj county, Romania), more precisely a căldărari Roma branch. The reason why I have chosen this group is the fact that they are known and perceived by the other branches and by the wider society to be the last branch that respects the majority (if not all) of Roma traditions, including the traditional ways of conflict resolution. From a total of 47 members, I had the opportunity to interview 12 of them, 5 women and 7 men, aged between 18 and 67 years old. Besides them, I interviewed one krisinitor (Roma judge; he can conduct any "Roma court"). All of the interviews were conducted after the observation stage. During this stage, I had the opportunity to discover and familiarize with the moral codes used by this community and to identify the members to be interviewed. These observations took place in various locations frequented by Roma, such as camps, residences, and fairs. This process took place throughout the entire data collection stage and should not be seen as a distinct phase of research.

\section{Traditional conflict resolution methods used by the Roma community in Romania}

Before any presentation of the findings of this study regarding the ways used by the Roma community in Romania to resolve the conflicts between its members, we must have a short discussion about their source. We saw at the beginning of this article that, like any other small community, the Roma people have a very strict moral code that governs the life of its members. For the Roma people, this is Romanipen. Romanipen is the set of values or codes that Roma have to follow to be a true Roma, as they called themselves. These values are based on four principles (or elements): honor, good fortune, family (actually understood as belonging to the whole community) and cleanliness/purity.

Honor (Pativ in Romani language) is a concept that introduces the basic values of the Roma community, values that must be respected with sanctity (respect, religious belief, shame). Honor is taught to children at a very young age. For example, if a child has a bad behavior, his family (especially the grandfather) will tell him "don't do that anymore, it's shameful". If the child asks why, the response will be "Because God sees you" and the child will stop his or her bad behavior. As we will also see in mechanisms of conflict resolution, the foundation of the Romanipen and its supreme value is (avoiding) shame.

Good fortune (Baxt in Romani language) represents the luck that a Roma person will have if he or she respects the moral code. More exactly, the baxt is a reward for respecting the Romanipen. Also, it is the first thing the Roma people will say to the other members, as a salute-Have good fortune. 
Phralipen is the sentiment of brotherhood and it refers to the fact that the whole community is in fact a big family. For this reason, the level of interaction and interdependence in a Roma community is very high. In the same regard, they respect all the other members (especially the elder ones). For a Roma person, a member of the community is a member of his or her family and they will protect that person in any given moment.

The last principle of Romanipen is the dichotomy between pure (uxo) and impure (maxrime). The whole life philosophy of the traditional Roma culture is based on this dichotomy, uxo meaning the respect for harmony and universal order. This dichotomy is based on the human body. The upper side of the body is considered pure and the lower one impure. From this, the Roma people established clear rules for hygiene, interaction between a man and a woman and interaction with the wider society.

Roma are often labeled as deviant. According to Richardson (2006), media discourse, police and politicians' actions make them socially so. However, while the Roma may sometimes appear to be deviants, Romanipen is strictly respected within the community. Compliance with this code is necessary for Roma as it enables them to gain status and good reputation within the community. According to the interviews conducted in the study, without a good reputation, a person would not be able to have a good and easy life inside the camp/town (he or she would have difficulties in selling products and founding a family). This is illustrated by the following fragment that refers to an incident where the person who violated the moral code has been ostracized by the other members of the community:

"... he is stained ... surely he won't be able to marry his children, let him say that his boys are okay but if he goes to ask for a bride, the doors are closed because of what he did ..."(personal communication, June 21, 2017).

Once a person's reputation has been lost, that person is seen as a gagiu, the term used for non-Roma people, and it is hard for them to be re-accepted in the community.

\section{Kris (Stabor) - the Romani court}

Anthropological studies have been influential in understanding the use of community courts employed by many small-scale communities (Scott, 1976; Gibbs, 1963; Bohannan, 1957). Drawing on Gibbs' (1963) study on the Kpelle tribe found in Liberia, Scott (1976) provides a useful definition of community courts and their proceedings, which he sees as informal assemblies set up to resolve disputes. Referring to these courts as "moots", Scott (1976) writes:

As a rule, the moot is convened as soon as the parties to the dispute can arrange to come together ... a mediator is agreed by both parties ... during these proceedings, the parties to the dispute are encouraged to express their complaints ... no one may leave the moot feeling embittered ... (pp. 610-611). 
As we can see from this definition, the purpose of the court is to seek an amicable resolution to a transgression, much like any other method inside the restorative justice movement, an important facet of the court being the restoration of the offender back into the community. What is evident from previous anthropological research is that a court or moot has greater influence over community members than the prevailing legal system of the state in which the community live. Indeed, Bohannan (1957) claimed that members of the Tiv failed to recognize the official state court of Nigeria. Similarly, Leach (1954) noted that the Kachin did not take the sanctions of the state courts seriously. Offenders punished by the state legal system would also be punished by their community on their return.

The use of informal community courts is not exclusive to tribal communities. Amongst Roma, these courts are referred to as Kris (Stabor in Romanian) and it would appear that this system has clear parallels to the ones outlined above: The Kris is basically a meeting of group members in which a specific conflict relating to inter-group relations, mainly between families, is discussed and some resolution of the dispute is reached (Caffery \& Mundy, 1997, p. 254).

Failure to comply with Roma customary values, of its community members, inevitably leads to the emergence of conflicts. Judgment occurs exclusively among members of the community. It is not possible to judge conflicts between members of the community and those from outside. In conclusion, the presence of non-Roma and of the authorities is not allowed. Conflicts are solved internally, through the Kris (Stabor), which has the role to reconcile parties and to solve conflicts arising from non-compliance of Roma traditions: disrespect for the pure-impure rules, stealing a girl, disrespect shown to an older person, adultery, insisting to look at a woman, uncovering the head by a woman, to name just a few. Under this system, the whole community is involved in the decision making and conflict resolution processes, because the responsibility of carrying out any sanctions belongs to the whole group.

The Kris is presided by one judge (known as krisinitor) or more, who has the role of a facilitator (similar to a mediator) more than the one of a judge. The krisinitor must be a person who knows the Roma's customs, practices, customs and traditions very well, be impartial, be a wise person, with a rich life experience, wealthy and enjoy the respect of the community. For the trial to take place, the judge (krisinitor) is paid by the person requesting the trial. If he/she is winning, the opposite party may have to repay and take care of the expense themselves. Judgment lasts three days: on the first day, the plaintiff and his witnesses are heard. The next day, the defendant is heard and on the third day the verdict is given. In the absence of evidence, vows may be requested - the vow on the life of a child is considered the most convincing one. In order to give the verdict, deliberations are needed, the jury retreating to a protected place in order not to be heard. The decision is not to punish but to compensate the harm, the aim being 
reconciliation and restoration of harmony in the community. This way of solving conflicts is one of the few common practices to traditional Roma, reflecting also the cult for elderly people, old age corresponding to wisdom and life experience.

If the community is not satisfied with the given verdict, if the community claims to know otherwise, or if the verdict arrives very late, an old woman can discredit the judgment by "raising her laps to her head". In this way, the judgment is annulled and the one who has requested the trial is obliged to leave the community or resume the trial with another judge. The same thing happens to the one who refuses to pay their debts as a result of the judgment. The goods remaining in the community - the house, the car, the furniture - belong to the one who won at trial.

In the past, during the period of nomadism, the judgment was made either by elders or by an old man and his wife remaining without a family in the camp, or, in the absence of the two situations, waiting until they met another satra (Roma group or family) and then gave the case to be judged. However, until that happened no one was allowed to open that case or talk about it. Everything was going on as if nothing had happened.

Another dimension of the Kris that needs to be explored here relates to the role of gender. In terms of gender, it was acknowledged that women played a pivotal role in ensuring that the family unit remains free from impurity. Yet, throughout the Kris, women play a minor role. It is not possible for women to bring a case directly to be judged. If they are in a dispute or have been the victim of an offence, it is the responsibility of the male members of her family to request this. Moreover, only in recent years women have been allowed to attend a Kris but are expected to just be silent observers.

\section{Fighting}

Fighting represents an important sanction among Roma, it is a system that is used when an individual or group have deviated from the moral codes of their community (Acton et al.,1997). For the Roma people, the fighting system is as important as the penal system is to the wider society and has more legitimacy among them. The reason for this is the fact that, for them, the ability to defend one's honor and that of their kin is incredibly important and the failure to do so is considered shameful (here we can draw a parallel between the concept of honor developed by the Roma people and duels, with swords or pistols, in order to defend one's honor, mostly in the $18^{\text {th }}$ and $19^{\text {th }}$ century).

Besides defending one's honor, the fighting system is a way to gain respect and status inside the community. More specifically, those who are great fighters are shown great respect by the whole community. However, these fights are often very intense and brutal. Yet, as Acton et al. (1997) recognized, the system of fighting employed by the Roma do not result in a continuous cycle of violence. The reason why things do not escalate is the fact that there are strict rules of fairness of the fights. One of these rules is the fact 
that weapons are not allowed, the fights happen barehanded. By doing this, the Roma preserve the fairness of the process and avoid deadly episodes. Another important rule is the fact that no one is allowed to interfere between the fighters in order to help them gain an advantage. Also, every fight has referees. The Roma fighting system involves also some rituals. One important ritual requires stripping to the waist and placing a silk bandana around the waist. This ritual is very important because it preserves the fairness of the fight.Often, the Roma men have these bandanas around their necks. By moving them onto their waists, no one can grab the other party by their neck neckerchief. All of them represent important rules and rituals but the most important one, as far as I could observe, is the fact that, due to the Romanipen, these fights are organized away from the children and women. Nobody is allowed to fight near a woman or a child; they must be protected and, at the end of the day, fighting is considered a "big boys" affair.

What is remarkable is the fact that, through their understanding of the rules and of the moral code, a continuous cycle of violence is avoided. Adherence to the rites and rituals is paramount as it is embedded within the moral code. Failure to do so will render an individual and their family unit impure, which will have repercussions on all aspects of their lives. For example, several members of the community observed for this study told me that nowadays the younger generation tend to use weapons (mostly bats and knives) and this is a very wrong thing to do because they become somewhat isolated from the rest of the community because they are seen as transgressing the old rules of fighting.

\section{Gossip}

Gossip, often in conjunction with labelling, is another technique used by the Roma community to informally resolve transgressions from the moral code (Okely, 2005; Bohannan, 1957). It appears that the role of gossip is fundamental in consolidating important values because it promotes social cohesion, with all members acting to avoid becoming the "target" (Gluckman, 1955). One of the most basic examples of gossiping and labeling for the Roma people are the non-Romas who are labeled as Gagii (Gadjo or Godje). Indeed, by using this word, the Roma people are able to distinguish between members and non-members. Language is also used within the community to mark out those who have broken the rules of this society. The Roma apply the term "læav" to those who transgress the moral boundaries held by members of the community (the term translates into "shame"). Anyone who is labeled in this way knows, along with the rest of the community, that they have brought shame onto the reputation of their families and of the community at large. As processes, labeling and gossip are basically, stories construed against a wrongdoer; rumors are then circulated from trailers, to camps and to visitors, with children playing a crucial role in passing on these rumors (Okely, 2005). Rumors continue until the offender recognizes their fault in public. Once this has happened, the rumors are stopped and the offender is accepted back into the community. During our research in the small community from Gorj county, gossip and 
labeling were recognized by the participants as being some of the basic forms of conflict resolution in their community. Even if to some of us labeling or gossip are considered "childish", to the Roma people it is a very important deterrent for bad behavior. As we can see from the following extract from an interview with a member of the community, the reason behind this is the interdependence between the members of the community and the notion of shame:

... it is a very close community, right, and once you've had this shame brought on your head then everyone is pointing fingers towards you and comments your actions and then you lose your respect... Losing your respect means that you'll have a hard time finding a wife for your sons, for example ... (personal communication, 2017, June 21).

... her daughter left the village with a white boy...it's a very big shame to do this in our community ... gypsy daughters must marry only gypsy boys ... she will be judged and kicked out of our village because she brought shame upon us... everyone is calling her this and that ... she doesn't have any future here ... this is her punishment (personal communication, 2017, June 21).

If we look carefully to these two fragments, we can understand that gossip is an important form of community justice that reinforces community values. On the other hand, gossip is also a form of shameful punishment, so members will avoid becoming a subject of gossip and of the shame that this brings on an individual and their family.

\section{Avoidance}

Another important sanction employed by many communities that is worth some attention here is avoidance. Avoidance and banishment allows the Roma to deal with those who fail to abide by the moral codes of their community.

There are two forms of avoidance as a sanction. Firstly, a sanction can be temporary, ranging from a couple of days to a couple of years, where transgressors are ostracized by their community for a specific period of time. During this time, the transgressor can remain in the community but nobody is interacting with him or he can be kicked out from the community for a specific amount of time. A harsher form of this sanction can see the wrongdoers permanently ostracized from their group. As in the case of most of the small-scale communities around the world, avoidance is not specific only to the Roma. Leach's (1954) study of the Kachin tribe in Burma showed how this community adopts the informal strategy of avoidance to deal with deviants, whereby deviants are ignored for a specific period of time. Similarly, the Chechens developed a range of sanctions such as avoidance, ostracism and exile for deviant transgressions.

In the case of the Roma in Romania, our study found that avoidance can take a number of forms, and more importantly, this mechanism has an important role in resolving 
conflict. On a basic level, avoidance can take the role of non-speaking relationships. Usually, this form of avoidance will be between members of different family units and requires that the whole family do not speak to anyone with whom they are in conflict. In more extreme cases, a family may be required to leave the village, either temporarily or permanently. In such cases, the conflict is never fully resolved as family members avoid attending any event which may involve the family with whom they are in conflict. By doing this, the sanction will continue until the deviant individual(s) amend their behavior. However, any form of apology would require recognizing the guilt and can have serious repercussions on an individual's reputation. In this sense, avoidance differs from the other mechanisms previously discussed. Indeed, within the tribunal and fighting systems, as long as both parties acknowledge and respect the rules and regulations, a truce is generally declared and the problem is resolved. Yet, with gossip and avoidance, disputes can be ongoing, often resulting in feuds.

During our research, we found a lot of interesting things regarding the system of avoidance but two of them must be mention here. During our observation and interviewing stage, we saw that when meeting a new member for the first time, members do not salute each other first but ask who each other's family is: "Whose family do you belong to?" or "Whose are you?". When we asked about the meaning of this, the reason they gave us was so that they could see if it was a family that they needed to avoid because of some ongoing dispute. Avoidance is so powerful that, if two families are in feud for generations, they will not attend even the most important events in the community births, marriages, and funerals. No member of a family can interact with one from the other family.

The second one is the relationship between avoidance and the four pillars of Romanipen, especially the fourth one - maxrime. When a person is ostracizes, it become maxrime, impure. By interacting with a maxrime person, a member of the community can become impure as well. Also, regarding the other three pillars, if you avoid an impure person, you respect your family and the community who punished the wrongdoer. By doing this, you have honor (the first pillar) which leads to having luck (the second pillar).

\section{Conclusion}

In understanding the system of justice practiced by Roma communities, the principles of restorative justice are applied, demonstrating the importance of shame within this system. In the case of Roma, the problem with shame is that if someone gains a poor reputation, that shame not only reflects on the individual but will also have bearing on their family and through the third pillar of Romanipen, to the whole community. Once a reputation has been lost, the person will be seen as a "Godje" a Gypsy term for a nonGypsy and it is hard for them to be accepted back. It is for this reason that the Roma abide by the strict moral code. As we mentioned in the case of Romanipen, shame is 
taught to children from early days because, being a small and closed community, the group is reliant on every member. At the end of the day, by respecting Romanipen and being afraid of shame, the community continues to function well. On the other hand, losing members due to shameful actions weakens the community and causes a lot of problems for the ones who are ostracized. As we can see, that would be a lose-lose situation that nobody wants.

Even so, maybe due to human nature, because of their socio-economic status or due to pure coincidence, sometimes Roma people transgress from their moral code. In such situations, the Roma developed their own system of justice comprising of swift and efficient ways of conflict resolution, based on the notion of shame. The methods adopted by the Roma are somewhat diverse and can range from fighting, gossip and avoidance to their specific community court - the Kris (Staborul). From our study and those of others before us, it seems that the likelihood of a person deviating from the code twice in a lifetime is very low, meaning that these methods function very well. Even if a harsh punishment can lead to a weaken community, the Roma told us that a community with "sick" members is weaker than one with less members who are "pure". One the other hand, evidence shows that Roma use the principles of restorative justice and built this justice system to reintegrate the wrongdoers back into the community.

\section{References:}

1. Acton, T., Caffery, S., \& Mundy, G. (1997). Theorizing Gypsy Law. The American Journal of Comparative Law, 45(2), 237-250.

2. Bancroft, A. (2005). Roma and Gypsy-Travellers in Europe: Modernity, Race, Space and Exclusion. Aldershot: Burlington VT.

3. Blagg, H. (2008). Crime, Aboriginality and the Decolonisation of Justice. Sydney: Hawkins Press.

4. Bohannan, P. (1957). Justice and Judgement Among TheTiv. London: Oxford University Press.

5. Chereji, C.R., \& Pop, A.G. (2014). Community Mediation. A Model for Romania. Transylvanian Review of Administrative Science, 41, 56-74.

6. Caffery, S., \& Mundy, G. (1997). Informal Systems of Justice: The Formation of Law within Gypsy Communities. The American Journal of Comparative Law,45(2), 251-267.

7. Coker, D. (2006). Restorative Justice, Navajo Peacemaking and Domestic Violence. Theoretical Criminology, 10(1), 67-85.

8. Colson, E. (1974). Tradition and Contact: The Problem of Order. Chicago: Aldine.

9. Coser, L. (1956).The Functions of Social Conflict. New York: Free Press.

10. Dawson, R. (2000). Crime and Prejudice: Traditional Travellers. Derbyshire: Robert Dawson.

11. Edwards, A., \& Hughes, G. (2005). Comparing the Governance of Safety in Europe. Theoretical Criminology, 9(3), 345-363. 
12. Gibbs, J. (1963). The Kpelle Moot: A Therapeutic Model for the Informal Settlement of Disputes. Africa: The Journal of the International African Institute, 33(1), 1-11.

13. Gluckman, M. (1955). Customs and Conflict in Africa. Oxford: Basil Blackwell.

14. Gmelch, S. B. (1986). Groups That Don't Want In: Gypsies and Other Artisan, Trader, and Entertainer Minorities. Annual Reviews Anthropology, 15, 307-330.

15. James, Z. (2005). Eliminating Communities? Exploring the Implications of Policing Methods Used to Manage New Travellers. International Journal of the Sociology of Law, 33(3), 159-186.

16. James, Z. (2006). Policing Space: Managing New Travellers in England. The British Journal of Criminology, 46(3), 470-485.

17. James, Z. (2007). Policing Marginal Spaces: Controlling Gypsies and Travellers. Criminology and Criminal Justice, 7(4), 367-389.

18. Leach, E. R. (1954). Political Systems of Highland Burma: A Study of Kachin Social Structure. London: Bell and Sons.

19. Lee, R. B. (1979). The !Kung San: Men. Women and Work in a Foraging Society. New York: Cambridge University Press.

20. Marshall, T. (1996). Criminal Mediation in Britain. The European Journal of Criminal Policy and Research, 4(4), 37-53.

21. Morris, R. (2001). Gypsies and Travellers: New Policies, New Approaches. Police Research and Management, 5(1), 41-49.

22. Okely, J. (1983). The Traveller Gypsies. Cambridge: Cambridge University Press.

23. Okely, J. (2005). Gypsy Justice Versus Gorgio Law: Interrelations of Difference. The Sociological Review, 53(4), 691-709.

24. Pfohl, S. (1981). Labeling Criminals. In L. Ross (Eds.), Law and Deviance (pp. 65-97). Beverley Hills: Sage.

25. Raybeck, D. (1988). Anthropology and Labelling Theory: A Constructive Critique. Ethos, 16(4), 371-397.

26. Richardson, J. (2006). Talking about Gypsies: The Notion of Discourse as Control. Housing Studies, 21(1), 77-96.

27. Scott, R. A. (1976). Deviance, Sanctions, and Social Integration in Small Scale Societies. Social Forces, 54(3), 604-620.

28. Stenson, K. (2005). Sovereignty, Biopolitics and the Local Government of Crime in Britain. Theoretical Criminology, 9(3), 265-287.

29. Vanderbeck, R. (2005). Anti-Nomadism, Institutions and the Geographies of Childhood: Environment and Planning. Society and Space, 23, 71-94.

30. Van-Ness, D., Morris, A., \& Maxwell, G. (2001). Introducing Restorative Justice. In A. Morris and G. Maxwell (eds.), Restorative Justice for Juveniles: Conferencing, Mediation and Circles (pp. 3-12). Oxford: Hart Publishing.

31. Walgrave, L. (2008). Restorative Justice, Self-interest and Responsible Citizenship. Cullompton: Willan Publishing.

32. Weyrauch, W. O. (2001). Gypsy Law: Romani Legal Traditions and Culture. London: University of California Press. 